\title{
ADSORPTION OF Cr (VI) FROM AQUEOUS SOLUTION BY USING CHEMICALLY MODIFIED AND UNMODIFIED SUGARCANE BAGASSE
}

\author{
ANURADHA SINGH ${ }^{\mathrm{a} 1}$ AND S.K. SINGH ${ }^{\mathrm{b}}$ \\ ${ }^{a}$ Department of Chemistry, A.N.D. Kisan P.G. College Babhnan, Gonda (U.P.), India \\ ${ }^{\mathrm{b}}$ Department of Chemistry, T.D.P.G. College, Jaunpur (U.P.), India
}

\begin{abstract}
Chromium (VI) is one of the highly toxic heavy metals. It is widely used in a number of industries like metallurgical, electroplating, paints, pigments, inks, fungicides and photography. It enters into the natural water bodies through the industrial effluents creating water pollution. Therefore its removal from waste water is considered to be very important. The removal of $\mathrm{Cr}$ (VI) by using agricultural waste as sugarcane bagasse from aqueous solution was investigated as a function of change in $\mathrm{pH}$ at temperature $28 \pm 1^{\circ} \mathrm{C}$, concentration $1.987 \times 10^{-4} \mathrm{M}$ and particle size $<55 \mu \mathrm{m}$. The removal of $\mathrm{Cr}$ (VI) on chemically modified sugarcane bagasse (MSB) was nearly $11 \%$ higher against unmodified sugarcane bagasse (USB). So the acidic pH of the medium promoted the rate of $\mathrm{Cr}$ (VI) removal on the adsorbent while inhibited at neutral or alkaline pH and gave good fit for adsorption kinetics equation during the study.
\end{abstract}

KEYWORDS: Adsorption, Chromium (VI), Sugarcane Bagasse

Water pollution due to toxic heavy metals has been a major cause of concern for environmental engineers. The industrial and domestic wastewater is responsible for causing several damages to the environment and adversely affecting the health of the people. Due to heavy metal contaminations in aquatic environment increased the awareness about the heavy metal toxicity and are considered as environmental priority pollutants which are targeted for cleanup processes. So the removal of toxic metals from sewage and industrial waste water is a matter of great interest in the field of water pollution, which is a serious cause of water degradation. (Rao et al., 2009). Chromium is commonly found in large quantities in tannery wastewater and also in small and medium scale industries. Therefore, the removal of $\mathrm{Cr}(\mathrm{VI})$ from polluted water bodies is a major problem and challenge at global level for the scientists. The metallic chromium and salts are widely used in industry in a variety of chemical processes. It is used in electroplating industry where it oxidizes electroplated metal surfaces to provide smooth, shiny and clean finishes. Some other products which contain chromium include paints, pigments, inks, wood preservatives, rubber ceramics, photography and textiles from where it is discharged into natural water bodies of water and lands.

The bulk application of chromium is in leather industry where it is used as a tanning agent chromium in waste water exists in two oxidation states viz $\mathrm{Cr}$ (III) which normally exist in the form of $\mathrm{Cr}(\mathrm{OH})_{2}{ }^{+}, \mathrm{Cr}\left(\mathrm{OH}^{-}\right)_{4}$ and $\mathrm{Cr}(\mathrm{VI})$ which exists in the form of $\mathrm{Cr}_{2} \mathrm{O}_{7}{ }^{2+}$ and $\mathrm{CrO}_{4}{ }^{2-}$ depending on the $\mathrm{pH}$ of the solutions. $\mathrm{Cr}$ (VI) is considered to be highly toxic compared to $\mathrm{Cr}$ (III). Due to its high oxidation potential it can easily penetrate biological membranes and cause health hazards. On contract $\mathrm{Cr}(\mathrm{IV})$ causes irritation, corrosion of skin and respiratory tract and lung carcinoma. Various physicochemical procedures are available for chromium removal from aqueous solution viz., precipitation, chemical reduction, ion-exchange electro chemical, evaporation, reverse osmosis and adsorption. However, among these, adsorption is found to be highly effective in expensive to operate at low concentration present in the waste waters (Jain et al., 2010; Adhene et al., 2014). India is an agricultural country and generates a considerable amount of agricultural wastes such as sugarcane bagasse, coconut juts nut shell, rice husk ash, rice straw, wheat straw, waste tea leaves, ground nut husk, peanut nulls and fertilizer wastes. The sugarcane bagasse one of the easily available agricultural waste which applied to removal of chromium as a adsorbent. Hence there exists a scope to try locally available low cost adsorbents for treatment of effluents containing $\mathrm{Cr}(\mathrm{VI})$. The various low cost adsorbent used for chromium removal reported by many investigators (Demirbas et al., 2004; Saritha et al., 2011; Bahadur and Mishra, 2014; Sharma et al., 2016; Ali et al., 2016; Sivakumar et al., 2017; Kumari, 2017; Karri et al., 2019; El-Baz et al., 2021). So on the use of

${ }^{1}$ Corresponding author 
agricultural by products as sugarcane bagasse as a good substrate for removal of metal ions from aqueous solutions and waste water. Chemical modification by the use of adsorbents increasing the efficiency of adsorbents. (Balaji et al., 2014) The present works describes on the study of the kinetics of metal sorption of $\mathrm{Cr}(\mathrm{VI})$ adsorption $\left(\mathrm{K}_{1}\right)$ at different $\mathrm{pH}$ values. The role of $\mathrm{pH}$ in $\mathrm{Cr}(\mathrm{VI})$ adsorption from aqueous solution in order to find out an appropriate $\mathrm{pH}$ range for maximum efficiency by using agricultural by products as sugarcane bagasse under chemically modified and unmodified condition were investigated during research work.

\section{EXPERIMENTAL}

The agricultural waste sugarcane bagasse which used as adsorbent was collected local market cane juice seller and the pith was separated manually. It initially was light yellow in colour. The sugarcane bagasse was boiled with water for 30 minutes in order to remove soluble sugars present. Then the waste water to be used in the investigation was prepared by dissolving a known amount of $\mathrm{K}_{2} \mathrm{Cr}_{2} \mathrm{O}_{7}$ (Potassium dichromate) in a known volume of distilled water in the order to have waste of uniform characteristics and to avoid the interference with order elements. To evaluate the potential of bagasse to remove $\mathrm{Cr}$ (VI) batch experiments were carried out. Then wastewater containing known concentrations of $\mathrm{Cr}$ (VI) were prepared from the stock solution and taken separately in the glass stoppered conical flasks. Then known quantities of the adsorbent were added to the waste water. The system was equilibrated by shaking the contents of the flask at room temperature. So that adequate contact time between adsorbent and the metal ion was maintained. The suspension was filtered through Whatman No.41 filter paper and the filtrate was analysed to evaluate the concentration of $\mathrm{Cr}(\mathrm{VI})$ metal in the treated waste water. All the analyses were performed according to standard methods (APHA, AWWA, WPCF, 1985 ) and the Cr (VI) metal analysis was carried out by using Atomic Adsorption spectrometry (Model: GBC902).

\section{Kinetic Study}

The kinetics of metal sorption studies of $\mathrm{Cr}(\mathrm{VI})$ were carried out for each adsorbent at different $\mathrm{pH}$ with initial concentration of metal ion solution was $1.987 \times 10^{-4}$ $\mathrm{M}$, particle size of the adsorbent was $<55 \mu \mathrm{m}$ and temperature $28 \pm 1^{\circ} \mathrm{C}$. Then a known amount of solution $(100 \mathrm{ml})$ was taken in $250 \mathrm{ml}$ Erlenmeyer flask, adsorbent $(0.5 \mathrm{gm}$ each) was soaked separately in the flask and agitated in a shaker for a fixed time and constant speed
(90 rpm). After agitation for an equilibrium period, the supernatant solution was filtered through whatman No.41 filter paper and uptake was determined spectrophotometrically by using filtrate. Then adsorption dynamics was calculated by taking adsorption rate constant. So the first order reversible reaction kinetics was used for the rate of reaction.

\section{RESULTS AND DISCUSSION}

\section{Effect of pH}

$\mathrm{pH}$ of a solution is regarded as a significant parameter in the adsorption of metal ions. The effect of $\mathrm{pH}$ on adsorption of $\mathrm{Cr}$ (VI) by agricultural waste as sugarcane bagasse (using chemically modified and unmodified) is presented in Figure 1 and Figure 2.

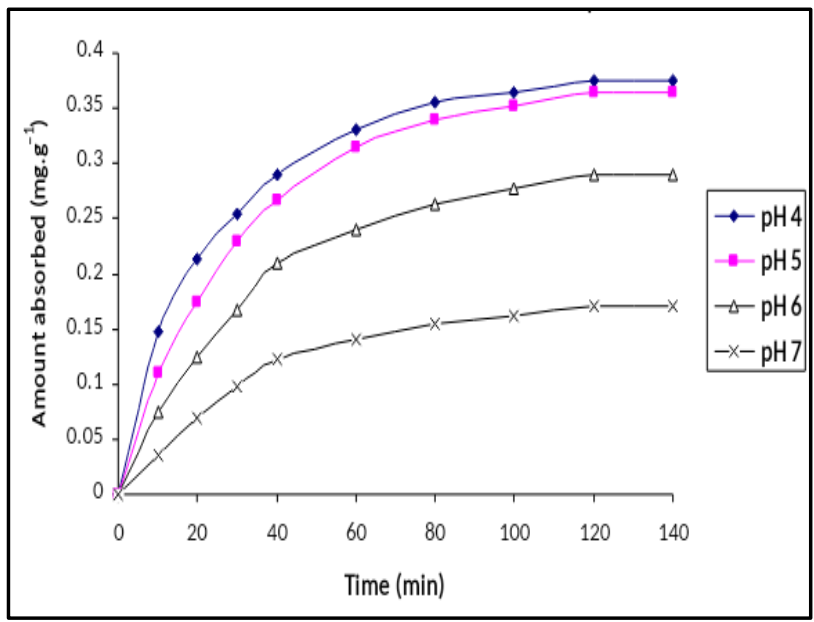

Figure 1: Effect of $\mathrm{pH}$ on adsorption of $\mathrm{Cr}$ (VI) by sugarcane bagasse unmodified (UB) at different time intervals (Temperature $28 \pm 1^{\circ} \mathrm{C}$; Concentration $1.987 \times 10^{-4} \mathrm{M}$, Particle size $<55 \mu \mathrm{m}$ )

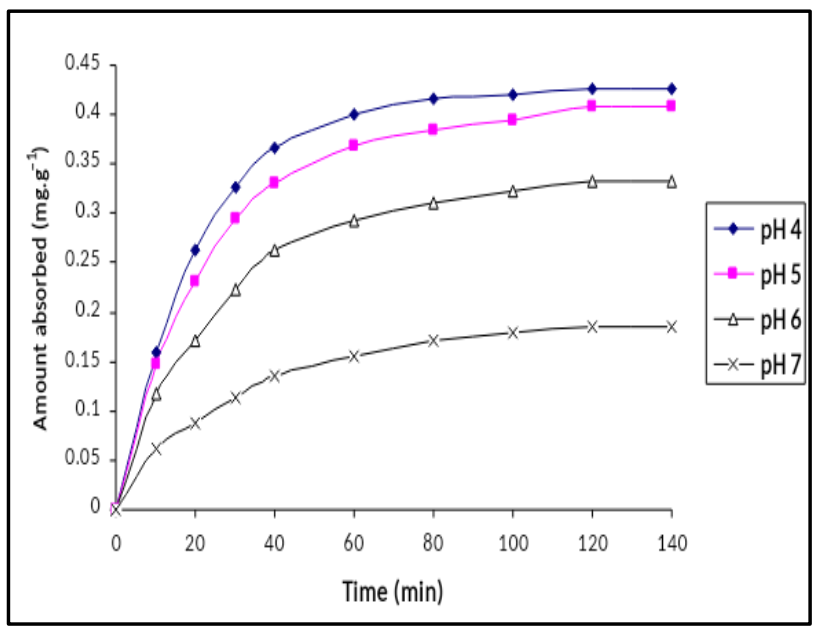

Figure 2: Effect of $\mathrm{pH}$ on adsorption of $\mathrm{Cr}$ (VI) by sugarcane bagasse modified (MB) at different time intervals (Temperature $28 \pm 1^{\circ} \mathrm{C}$; Concentration $1.987 \times 10^{-4} \mathrm{M}$, Particle size $<55 \mathrm{~m}$ ) 
The change in $\mathrm{pH}$ of the solution has no effect on the basic nature of the time growth adsorption curves and period of saturation. The time growth adsorption of $\mathrm{Cr}$ (VI) by two adsorbents suggested that the removal was initially rapid and finally become constant due to the slow removal near saturation. This variation in percent adsorption at different $\mathrm{pH}$ by each adsorbent. The change in $\mathrm{pH}$ of the solution has no effect on the basic nature of the time growth adsorption curves and saturation periods as shown in Figure 1 and Figure 2. However, the extent and rate of adsorption vary significantly with change in $\mathrm{pH}$ of the medium and modification of the sugarcane bagasse adsorbent. The adsorption of $\mathrm{Cr}(\mathrm{VI})$ an unmodified (normal) sugarcane bagasse (UB) the extent of removal changes from $75 \%$ to $34 \%$ and adsorption rate constant $\left(\mathrm{K}_{1}\right)$ from $0.0374 \mathrm{~min}^{-1}$ to $0.01952 \mathrm{~min}^{-1}$ at $\mathrm{pH} 4$ and $\mathrm{pH} 7$ respectively with optimum velocity at $\mathrm{pH} 4$. However, the percent adsorption was significantly increased with chemically modified sugarcane bagasse (MB) at the same $\mathrm{pH}$ as in (Figure 1 and Figure 2). The adsorption was decreased from $85.20 \%$ to $37.20 \%$ at $\mathrm{pH}$ 4 and 7 respectively with adsorption rate constant 0.0374 $\min ^{-1}$ to $0.01952 \mathrm{~min}^{-1}$. Overall rate constant $\left(\mathrm{K}_{1}\right)$ and rate constant of adsorption $\left(\mathrm{K}_{1}\right)$ at different $\mathrm{pH}$ for both adsorbent (UB \& MB) was shown in Figure 3 and Figure 4.

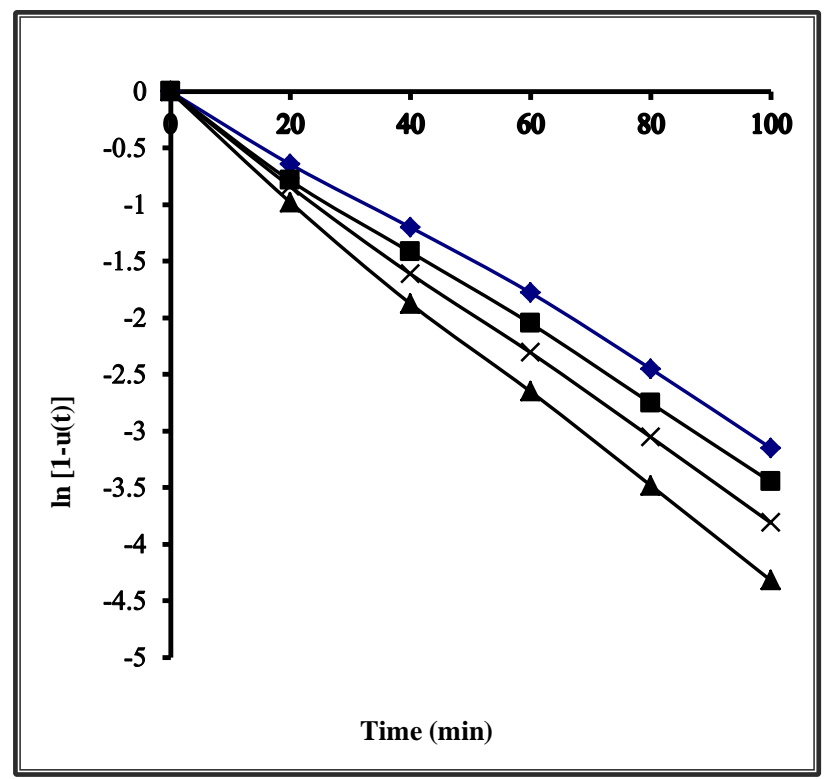

Figure 3: Rate constant plot for adsorption of $\mathrm{Cr}$ (VI) on sugarcane bagasse (unmodified) at different pH

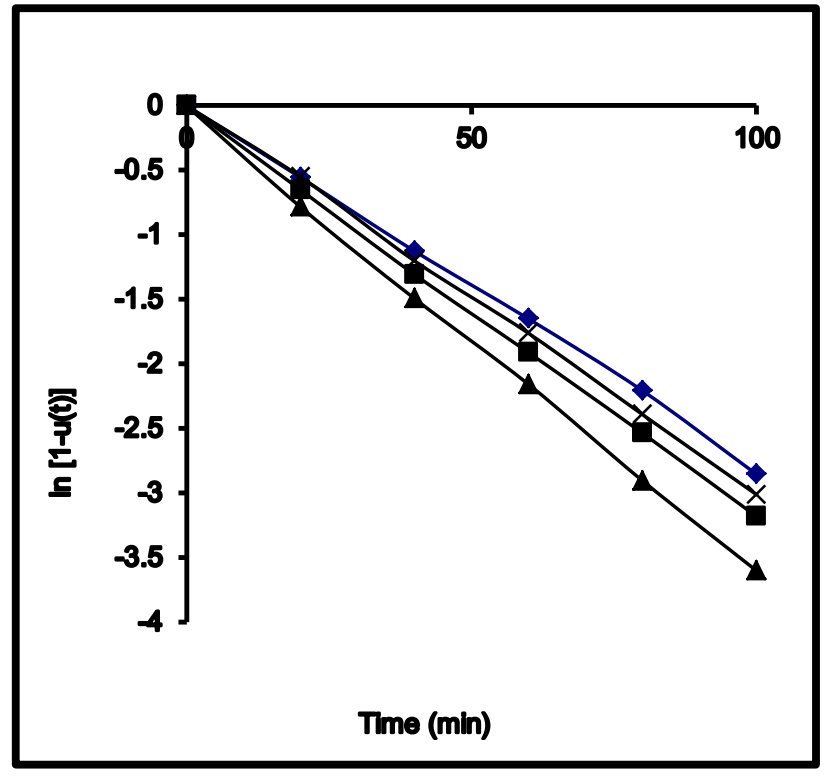

Figure 4: Rate constant plot for adsorption of $\mathrm{Cr}$ (VI) on (modified) sugarcane bagasse at different $\mathrm{pH}$

\section{CONCLUSION}

Therefore, it is obvious from the results that $\mathrm{pH}$ of the medium affected the rate constant in accordance with extent of adsorption. The maximum adsorption has been noticed at $\mathrm{pH} 4$. So there is an exponential decrease in the extent of adsorption with increase in $\mathrm{pH}$ (4 to 7). At $\mathrm{pH} 4$ where maximum uptake of $\mathrm{Cr}$ (VI) has been noticed in both the conditions of the adsorbents (UB \& MB) there exists a significantly high electrostatic attraction between protonated adsorbent surface and negatively charged adsorbate species. So the results in a high driving force for the formation of surface complex or their presence as chromates on the surface adsorbents. At $\mathrm{pH} 4$ where maximum uptake of $\mathrm{Cr}(\mathrm{VI})$, there is an possibility of the dissolution of substrate and whose constituents cause surface precipitation of chromate. During in acidic condition the uptake of $\mathrm{Cr}$ (VI) by these adsorbents (UB $\& \mathrm{MB})$ is expected due to solid solution interface. Therefore, more adsorption of $\mathrm{Cr}$ (VI) by chemically modified sugarcane bagasse (MB) might be due to increase in surface area which has great effect on sorption capacities of adsorbents. So the use of low cost agricultural adsorbents can also minimize cost inefficiency contribute to the sustainability of the environment.

\section{REFERENCES}

Adhene A.W., Nigus G.H. and Hayelon D.B., 2014. Removal of hexavalent chromium from tannery wastewater using activated carbon primed from sugarcane bagasse: adsorption/desorption 
studies. American Jr. of Applied Chemistry, 2(6): 128-135.

Ali A., Saeed K. and Mabood F., 2016. Removal of chromium (VI) from aqueous medium using chemically modified banana peels as efficient low-cost adsorbent. Alexandria Eng. J. (Internet), 55(3): 2933-42.

APHA, AWWA, WPCF, 1985. Standard methods for the examination of water and waste water analysis, Washington D.C.

Bahadur K.D. and Mishra P., 2014. Adsorptive removal of $\mathrm{Cr}(\mathrm{VI})$ from aqueous solution by sugarcane biomass. Research Journal of Chemical Sciences, 4(5): 32-40.

Balaji R., Sasikala S. and Muthuraman G., 2014. Removal of Iron from drinking / ground water by using agricultural Waste as Natural adsorbents Int. Jr. of Engineering and Innovative Technology (IJEIT), 3:12.

Dehghani M.H., Sanael D., Ali A. and Bhatangar, 2016. Removal of $\mathrm{Cr}$ (VI) from aqueous solution using treated waste newspaper as a low-cost adsorbent: Kinetic modeling and isotherm studies. J. Mol. Liquids, 215: 671-679.

Demirbas E., Kobaya M., Senturk E. and Ozkan T., 2004. Adsorption kinetics for the removal of Chromium (VI) from aqueous solutions prepared from agricultural waste. S.A. 30(4): 533-539

El-Baz A.A., Hendy I., Dohdoh A.M. and Srour M.I., 2021. Adsorption of High Chromium Concentrations from Industrial Wastewater Using Different Agricultural Residuals Journal of Environmental Treatment Techniques, 9(1): 122-138.

Garg U.K. and Sud D., 2005. Optimization of process parameters for removal of $\mathrm{Cr}(\mathrm{VI})$ from aqueous solutions using modified sugarcane bagasse. EJEAF Che. Journal, 6:1150-1160.

Jain M., Garg V.K. and Kadirvelu K., 2010. Adsorption of hexavalent chromium from aqueous medium onto carbonaceous adsorbents prepared from waste biomass. J. Environ. Manage 91(4): 949 957.

Karri R.R., Sahu J.N. and Meikap B.C. 2019. Improving efficacy of $\mathrm{Cr}$ (VI) adsorption process on sustainable adsorbent derived from waste biomass (sugarcane bagasse) with help of ant colony optimization. Ind. Crops Prod. [Internet]. 143:111927.

Kumari P., 2017. Application of Sugarcane Bagasse for the Removal of Chromium (Vi) and Zinc (Ii) From Aqueous Solution. Int. Res. J. Eng. Technol., 4(6): 1670-73.

Rao M.M., Reddy D.H, Venkataswarlu P. and Sesnaish K., 2009. Removal of Mercury from aqueous solutions using activated Carbon prepared from agricultural by- product/waste. Environ J. Manage, 90(1):634-643.

Saritha B., Singh A., Amson, Jha D. and Khriezokiso, 2011. Adsorption of chromium (vi) from aqueous solution using sugarcane bagasse as adsorbent. International Journal of Engineering Trends and Technology (I.J.E.T.T.), 2(3):2.

Sharma P.K., Ayub S. and Tripathi C.N., 2016. Isotherms describing physical adsorption of $\mathrm{Cr}(\mathrm{VI})$ from aqueous solution using various agricultural wastes as adsorbents. Cogent Eng. [Internet], 3(1):1-20.

Sivakumar D., Shankar D., Mahalakshmi R. and Deepalakshmi K., 2017. Kinetic Model Studies on Removal of Hexavalent ChromiumSugarcane Bagasse Powder. Int. Res. J. Multidiscip Sci. Technol., 2(5):37-43E. 